\title{
Capítulo I7 \\ Comunicación y aprendizajes: \\ notas para promover experiencias \\ educativas en la ciudad
}

\author{
Genaro Aguirre Aguilar* \\ UNIVERSIDAD VERACRUZANA
}

Producto de la reflexión y su experiencia docente, el texto busca proponer una lectura sobre la ciudad, en donde los encuentros vividos por su gente, devengan actos de reinvención cotidianos. Asumir los contextos urbanos como sitios para la producción de aprendizajes, es convertir a la ciudad en un lugar que posibilita relaciones sociales y puede orientar hacia otro tipo de ciudadanía.

Product of the reflection and the teaching experience of the author, the text searches for the propose of reading about the city, where the lived encounters by its people, wandered acts of daily reinvention. Assuming the urban contexts as sites for the production of learning, is to turn the city into a place to make social relationships possible that may guide other kind of citizens.

* El autor es maestro en comunicación por la Universidad Veracruzana. Candidato a Doctor en Sociedades multiculturales y estudios interculturales por la Universidad de Granada. Docente de Tiempo adscrito a la Facultad de Ciencias de la Comunicación de la Universidad Veracruzana. Es autor de los libros Los usos del espacio nocturno en el puerto de Veracruz y Pistas para abordajes cualitativos. Manual teórico, práctico y técnico, ambos editados por la Universidad Cristóbal Colón, además de diversos artículos publicados en revistas de circulación nacional e internacional, así como en compendios colectivos. Ha sido Jefe del Departamento de Investigación de la Universidad Cristóbal Colón. Desde 1998 es comentarista especializado en comunicación, sociedad y cultura en Noticiarios de la $U$ del Grupo Pazos Radio, en la ciudad de Veracruz. 


\section{DE LAS PRIMERAS APUESTAS}

Haciendo memoria, es posible reconocer que los lugares en donde el hombre ha vivido a lo largo de los tiempos, han sido profundamente importantes en la generación de los saberes y el desarrollo de competencias que le han permitido dar continuidad y hallar el sentido a su existencia.

Traer aquí una imagen como esta, tiene como intención realizar un ejercicio en el que el pensamiento navegue en los recuerdos para volver sobre sus pasos y comprender que las dinámicas y maneras de socialización que han caracterizado al hombre desde siempre, son formas estratégicas de interacción, en las que la razón junto a la inventiva han promovido actos creativos que pudieron rayar en un pensamiento reflexivo.

El atrevimiento para pensar que esto es posible, es en reconocimiento a que todo acto creador es lúdico, estético, imaginativo pero que bien puede andar en los umbrales de un ejercicio fenoménico. No hay que olvidar que un acto creativo, permite al pensamiento arborecer y producir, por lo tanto representar un tipo de configuración del mundo, social y de vida de hombres o mujeres. Alcanzar esto, le supone al ser humano colocar en el horizonte de su percepción y su razón, una forma de re-creación de los escenario sociales, recreación alimentada por lo que le rodea, por lo que cree y es capaz de aprehender en la interacción cotidiana; ámbito vital en donde los contornos del espacio social permiten poner, codo a codo, otredades.

Por supuesto que aceptar o siquiera atreverse a pensar en esta posibilidad no resulta fácil, particularmente acostumbrado como está el pensamiento a construir lecturas desde la fragmentación y la dicotomía. No obstante, en el espíritu de este trabajo, está precisamente apostar por ello como mera posibilidad, sin dejar de atraer los aperos conceptuales que vayan allanado los temores propios que supone poner en común ideas como las que se develan a continuación.

Es decir, el objetivo de este texto es plantear la necesidad reconocer que la ciudad y sus espacios, ofrecen la ocasión para que nuestros encuentros sociales generen los aprendizajes que faciliten la constitución de un sujeto capaz de potenciar su ciudadanía; para lo cual la comunicación en la educación puede ser el dispositivo que medie los procesos. Para esto, entendemos a la mediación como "la tarea de tender puentes entre lo que se sabe y lo que no se sabe, entre lo vivido y lo por vivir, entre la experiencia y el futuro." (Prieto Castillo, 2004, p. 95) De allí que sea necesario desbordar los lugares formales de la enunciación de los conocimientos, para poder apropiarnos mejor los entornos urbanos, 
intensos para el aprendizaje y densos en lo comunicativo; en cuyo centro epistemológico, siempre deberán estar la pluralidad y la diversidad cultural, como constantes incorporadas a los procesos de interacción educativos.

\section{LA CIUDAD, LOS SUJETOS Y ALGUNAS OTRAS COSAS}

En la suma de perfiles y quehaceres de los sujetos que cohabitan en los espacios urbanos, se encuentran tipos de saberes edificados en distintos frentes, constancia de la efervescencia propia de sociedades urbanas en las que la modernidad pudo llegar a trompicones pero propiciando experiencias constructivas en las vidas de sus habitantes.

De tal suerte que, del saber ordinario al científico, del conocimiento informal al legitimado por lo institucional, de la racionalidad a la sensibilidad lúdica, estamos ante verdaderas prácticas sociodiscursivas que erigen mundos posibles, continentes de expresividad sobre los cuales la promoción de formas de construcción de lo humano atraviesa el puñado de estadios por donde el hombre mismo se piensa y genera formas de socialización y representación de sus realidades. Del mundo social al mundo de vida, se observan una diversidad de mecanismos, estrategias y tácticas para interactuar y hacer visible una pluralidad cultural que se recrea en las muchas zonas viandantes y de producción de sentido, en las que la palabra toma por asalto universos de interacción para tratar de especificar, de colocar marcas, de legitimar actos y conocimientos productos de la experiencia humana.

Se tiene entonces que así como el científico toma del universo lingüístico aquellas formas para construir un universo discursivo que lo visibiliza y legitima; así como el poeta encuentra en las palabras las tácticas de transformación de lo observado, sentido e imaginado; así como el compositor muestra su oficio para trazar sobre el pentagrama las notas que den sentido y expresividad armónica a una obra musical; así como la persona común se hace de maneras inteligibles para tratar de entender y explicar los pasajes de su vida cotidiana, así también los habitantes de las ciudades pueden llegar a entenderla y concebirla como un lugar estratégico para la construcción de un tipo de cotidianeidad capaz de producir una experiencia propia de un usuario urbano habilitado para aprovechar sus encuentros y con ello posibilitar un sentido de pertenencia distinto; de allí la necesidad de trabajar en la definición de ese sujeto capaz de asumir la necesidad de procurar escenarios de encuentros que potencien aprendizajes junto a los muchos otros sujetos con quienes teje el entramado y la gramática urbana. 
Para lograr esto, los procesos de socialización e interacción develadas cotidianamente en las ciudades, se tendrían que asumir como constructos históricoculturales capaces de reinventar las dinámicas del todos los días, ello en aras de una búsqueda constante de entendimiento entre el "nosotros" y el "otro", pero sobre todo, ese "Otro" que -como dijera Jesús Martín Barbero- interesa porque es capaz de indigestar, de desestabilizar la propia existencia del "nosotros"; "no el otro que está ahí, y yo lo veo y digo <qué lindo>” (2005, p.13). Es decir, sumar a los mundos de vida a aquellos agentes que -por azares del destino o decisión propia- les ha tocado (sobre) vivir en una ciudad, contribuyendo al sentido de una alteridad que trastoca las formas de representación y existencia colectiva. Es de esos procesos naturales de convivencia, heterogeneidad y distinción, que los seres humanos podemos configurar territorios para el aprendizaje, a través del toque mágico que representa la búsqueda, el asombro y las tácticas creativas.

\section{Ciudades Para dialogar, escenarios Para APRENder}

Para nadie es un secreto que hoy día las ciudades han pasado a ser el lugarsigno de lo contemporáneo (Giddens, 2004; Borja y Castells, 2002; Ianni, 2000; Auge, 1995), ese continente capaz de objetivar pensamiento y acción en un tiempo en el cual la incertidumbre, el hedonismo, el individualismo, la violencia en sus muchas formas, lo efímero como condición de abordaje diario, corren por delante; pero igual ese mismo en el que emergen de vez en vez una serie de expresiones de solidaridad, de fraternidad, de comunicabilidad propia de un pensamiento tozudo, propositivo que aboga por la puesta en común de proyectos compartidos; empleando plataformas y circuitos dotados por la llamada sociedad red, aun en medio del acertijo, la incertidumbre y lo contradictorio que todo esto suponga, incluso, sin importar que tales comunidades de usuarios provengan de la periferia y bien a bien no sepan en qué consiste la tan nombrada sociedad de la información.

Esta suerte de "esquizofrenia" posmoderna, convierte a la ciudad en un continente geográfico que por su por naturaleza representa un "frente cultural" (González, 2003, p. 157-195), en cuyos pasadizos urbanos (calles, barrios, fraccionamientos, unidades habitacionales, zonas de asentamiento irregular), perviven formas claroscuras de la urbe, pliegues, contextos ring side en el que la vitalidad y la energía propia de lo ideológico urbano, plantean mecanismos para suscribir y representar la ciudad; pasando a convertirla en una suerte de "personaje idílico" de una modernidad efímera, evanescente. 
De mapas a itinerarios, de historias colectivas a trayectorias personales, estamos ante la conformación de una trama cultural articulada por experiencias de urbanidad lo mismo que de humanidad, en el que fantasías y quimeras se agazapan para enfrentarnos a la vuelta de cualquier esquina. Por ello, las cartografías de la existencia en las ciudades, son mapas, marcas, anclajes cognitivos a través de los cuales la heterogeneidad, las asimetrías, las diferencias y los distingos de los sujetos sociales dan cuenta de una multiculturalidad vertebradora de formas de representación y expresión de sus ciudadanos.

Estamos entonces frente a una cualidad geosimbólica (Giménez, 1996) de toda ciudad, la misma que permite la articulación de un denso entramado de comunicabilidad en la que las interacciones de diverso cuño, las focalizadas y aquellas que no lo son (Joseph,1999), los imaginarios colectivos y las prácticas sociales, terminan por desbordar la institucionalidad sobre la que fueron concebidas, planeadas y erigidas para ser recreadas, reinventadas, resignificadas por los usos que de ella hacemos sus habitantes.

Por ello, valdría la pena preguntar ¿es posible imaginar a la ciudad como un lugar capaz de generar las condiciones para construir escenarios de diálogo y aprendizaje?, ¿es propio de un sujeto social urbano producir conocimientos que sean la suma de una razón alimentada lúdica y éticamente para enfrentar los designios de su ciudadanía?, ¿a través de qué estrategias la comunicación y la educación pueden redimensionarse para posibilitar entre los habitantes de la ciudad un tipo de estética vital capaz de construir puentes entre una actitud despreocupada y acciones razonadas que permitan experiencias diversas?, ¿es posible que en medio de la fragmentación y el aparente "dominio" de los no lugares (Auge,1995), podamos desarrollar mecanismos y estrategias de reconocimiento para alcanzar los umbrales de una conciencia histórica en el presente?

\section{TEXTOS Y METÁFORAS QUE RECREAN LA VIDA EN LAS CIUDADES}

La supremacía de un modelo económico que ensombrece alternativas al venderse como único posible, encuentra su lugar de reproducción en las inercias, las ilusiones y las falacias del bienestar y las libertades humanas. Los medios de comunicación tanto como la circulación de bienes y servicios junto a los mercados y las formas de consumo, han pasado a ser potentes agencias de mediación que legitiman formas de vida en las que lo visible, lo tangible, lo material alcanzan rangos simbólico. He aquí que la imagen es el lugar para la confirmación de aquellos signos que son la evidencia de un periodo histórico 
que ha alterado nuestras vidas. De la posmodernidad a la modernidad líquida (Appadurai, 2001) se nos presenta un mundo desbocado (Giddens, 2004), cuya tipificación encuentra en las plataformas tecnológicas de comunicación, los vehículos para instrumentar la interactividad mediática, reproduciendo estrategias de deslocalización de lo humano, al reproducir formas esencialmente despersonalizadas, virtuales, efímeras como propiedades intangibles de una era del vacío (Lipovetski, 2004), en la que los marcos axiológicos universalmente aceptados han ido trasmutándose todos los días, para ser hoy otros y bastante distintos a los históricos. Es precisamente en un contexto como éste, que se acuñan estilos de vida, maneras emergentes de ser que son muestra de nuestros hábitos y comportamientos "institucionalmente" determinados.

Pero igual aparecen discursos venidos de frentes tan distintos que suelen ser periféricos o apocalípticos, que anuncian el aniquilamiento de formas culturales, de costumbres, de tradiciones que, si bien han sobrevivido a los embates de una historia de sometimiento, hoy viven enfrentando un deterioro ante la falta de representación o apropiación entre las nuevas generaciones de ciudadanos. Otro tipo de discurso es aquel que sobredimensiona irreflexivamente los tiempos que corren, al reducirlos a sus aspectos macroeconómicos, no alcanzando a comprender la incidencia -no siempre positiva- en procesos menores y en cualquier reducto de nuestra vida cotidiana. ¿Cómo pensar igual que antes cuando lo tradicional apenas es aliento en medio de formas de vida y relaciones que han aprendido a vivir en medio de otros lenguajes y por ente otras realidades?

No obstante el entendimiento de estas posturas contradictorias, creemos en los hallazgos, en mecanismos, estrategias y tácticas para reinventar el mundo de cara a una complejidad que exige pensamientos y acciones que posibiliten otros escenarios y alcanzar a configurar un sujeto capaz de indagar en otros estadios de aprendizaje. Pensar lo contrario, es clausurar los horizontes, arrodillar la capacidad de asombro, morir sin intentar siquiera imaginar las formas de "abrir los mares" para conducirnos por una vida, donde el ser humano, la búsqueda de libertades, la confianza en el otro, la creencia en una "comunidad de destino" (Bauer en Morin, 2002) sean narrativas para seguir adelante.

Precisamente, son las lecturas sobre las ciudades y sus ámbitos de socialización que hagamos, los primeros momentos para la recreación de espacios de diálogo y aprendizaje, ya que son los continentes citadinos, lugares en los que se revelan porosidades, pliegues, intersticios, por donde asomarse a formas de producción de sentido que pudieran desbordar en actos reflexivos para el entendimiento, la explicación y el reconocimiento de lo que significa 
-en el ámbito cognitivo, experiencial y vital- ser actores de y en la ciudad. En ella, cada evento, cada elemento, cada agente articula no sólo lo urbano sino también lo humano. Al final del día de lo que se trata, es de conformar una agenda que contribuya a la canalización de experiencias de vida que alimenten, que representen aprendizajes ciudadanos. Pero ¿es posible el establecimiento de esa agenda?, ¿cuáles serían los mecanismos, las estrategias, las decisiones para consolidar esto?

\section{Agenda E ITINERARios PARA RE-CREARSE EN LA CIUDAD}

Los nodos, bucles, interfases en los que el ciudadano urbano se mueve y a través de los cuales se conecta con el "allá afuera" y el "aquí dentro", son la representación de un entramado comunicacional complejo que demanda acompańamientos, andamiajes razonados, creativos para orientar el perfil de un tipo de sujeto capaz de responder a las demandas de un conocimiento pertinente en el que los reconocimientos de otredades, faciliten un tipo de socialidad intercultural como cualidad de toda urbe. Para ello, siempre será necesario reconocer la complejidad de los escenarios contemporáneos, por lo que los lugares y espacios citadinos tendrían que asumirse como zonas de estar y transferir, para intercambio de vivencias y sentidos, en cuya matriz estarían procesos educativos de muy diversa índole (formales, informales o no formales), pero que permitirían la arborescencia de la vida en comunidad, del diálogo y la generación de una ciudadanía. Se trata de atreverse a creerlo.

Se demandan -entonces-- actos de gestión colaborativa capaz de administrar las coincidencias o divergencias propias de realidades plurales, las mismas que plantean decisiones, acciones en el marco de mundos de vida en donde las conciencias prácticas deambulen para posibilitar mecanismos, formas o tácticas de sobrevivencia en un mundo fragmentado, pero siempre en la búsqueda de un destino común: la gestión y la administración de la propias experiencias urbanas en aras de aprendizajes pertinentes.

En los umbrales de una reflexividad posible, las personas venidas a sujetos urbanos, tendrían que reconocer la importancia del papel que juegas los espacios urbanos como lugares de mediación social para mejor aprovechar lo que detrás de cada uno de ellos existe. Para esto, la comunicación en la educación tendría que ser uno de los dispositivos prominentes en la gestión de aprendizajes, para así ensanchar las formas de relación fenomenológica que realizamos los viandantes cuando tejemos el acontecer diario. 
Optimizar los procesos desde los ámbitos educativos, demanda de sus agentes la reconsideración de expectativas, proyectos, apuestas individuales para poder generar modelos y estrategias de promoción de saberes compartidos. La intervención en los aprendizajes emanados de las experiencias cotidianas podría encontrar en la mediación, acciones para alcanzar los conocimientos que demandan las nuevas formas de visibilidad y convivencia aquí planteadas. Cada rincón, cada espacio de socialización, cada acto, cada interacción, tendrían que representar ámbitos de interlocución dialécticos; esos en los que la diversidad, las distinciones, las mismas asimetrías culturales, las biografías grupales e individuales, sean detonadores de saberes.

Para esto, el razonamiento, la estética, la capacidad de un pensamiento que sume y no que reste, tendría que buscar las maneras para la conformación de anclajes comunes y establecer comunidades de sentido, en las que la administración de inteligencias múltiples, polivalentes, tengan que ver con estrategias de apropiación de los saberes producidos y recreados en las representaciones, los imaginarios, los discursos y las prácticas de los habitantes de toda ciudad.

A partir de aquí, tendríamos que articular estrategias de mediación e intervención entre los sujetos y aquellos agentes que vienen promoviendo lugares distintos a aquellos que producían el saber tradicional, pues no hay que olvidar que no es tanto el libro como la imagen (Martín-Barbero, 2002, p. 45-77) quien detentan un capital educativo en estos momentos. Preguntas oportunas serían: ¿En el terreno de la formalidad académica, la comunicación ha reconocido el papel que como vector puede tener hoy cuando se habla de la deslocalización y el descentramiento de los lugares de producción de saberes?, ¿acaso la educación formal ha dimensionado o implementado estrategias de relectura de los universos simbólicos construidos diariamente en la ciudad en el que la interpelación tecnológica viene exigiendo distintas inteligencias? No lo obviemos: la cultura letrada ha venido perdiendo camino ante la cultura audiovisual y eso es un signo de los nuevos tiempos que no se puede ignorarse en aras de seguir manteniendo un capital intelectual cada vez más desdibujado. Los estudiosos de la comunicación, deberíamos tener la mayor claridad al respecto. ¿Va siendo así? Las dudas pueden ser muchas.

\section{Dispositivos PARA APRENDIZAJES EN UNA ZONA COSTERA}

En la ciudad de Veracruz, esa del rostro urbano que se deja golpear cada mañana por una brisa que viene del Golfo de México, en los últimos 15 años han venido 
sucediéndose una serie de fenómenos que tienen que ver con el ensanchamiento de la mancha urbana, así como los densos procesos de socialización propios de una ciudad que ha recibido en su seno a emigrantes venidos de experiencias culturales diversas. Esta movilidad humana de la que hemos sido testigos, ha convertido al puerto (como seguramente ocurre a muchos otros lo mismo que a otras tantas ciudades) en un lugar donde discursos y prácticas construidas por comunidades cubanas, españolas, árabes, italianas, asiáticas, nacionales ${ }^{1}$ -en mayor o menor medida-, han encontrado un territorio para ser apropiado y resignificar costumbres, ritos, tradiciones culinarias, formas musicales o dancísticas que devienen alimento en la generación de aprendizajes, al desarrollar la capacidad de conciliar historias venidas de trayectos multiculturales e itinerarios interculturales de distinto cuño.

Siendo un puerto de carga y que goza de la venia de un porcentaje de turistas nacionales, Veracruz en los últimos años también se ha convertido en un municipio hermanado por la colindancia con la ciudad y municipio de Boca del Río, conformando una zona conurbada que, cada vez más por su extensión hacía algunos puntos cardinales, comienza a configurar una zona metropolitana por sus vínculos territoriales y de desarrollo urbano con ciudades como Medellín y Alvarado. No obstante, antes que se consolide en zona metropolitana, la conurbación entre Veracruz y Boca del Río, ha permitido la generación de un equipamiento urbano en el cual la infraestructura en los servicios, las ofertas culturales, los espacios de socialización, las estrategias de visibilidad de sus habitantes, los mecanismos para el consenso y la interacción, muestran los alcances de una gramática cultural propia de un par de ciudades cobijadas por la era de la globalización y todo lo que esta palabra venga a significar.

En ellas, la vida pública y privada, pervive al amparo de la manufactura modernista, de una arquitectura donde lo "cosmopolita" aún no encuentra del todo su identidad pero que se levanta a contrapelo de una racionalidad venida de muchos frentes. Los edificios de hormigón, las unidades habitacionales, los fraccionamientos, los centros comerciales, los complejos cinematográficos, los corredores gourmet, se han sumado al paisaje de ambas ciudades para dejar que del centro a la periferia, este tipo de espacios desarticulen el ideal de territorialidad al que sus habitantes estaban acostumbrados. La idea del barrio, de la

${ }^{1}$ En este contexto, cuando hablamos de comunidades nacionales reconocemos los grupos étnicos que han alimentando la memoria histórica de nuestro pueblo y que en un contexto como el veracruzano, suman identidades para contribuir en el colorido de nuestros paisajes locales.

Comunicación y aprendizaje: notas para promover experiencias educativas en la ciudad $\bullet 373$ 
colonia, del "rumbo" hoy son recuerdos ante la avasallante avanzada de unidades habitacionales, de fraccionamientos y la edificación de novísimos espacios urbanos que son el caldero en la construcción de nuevas territorialidades, identidades y formas de representar el sentido del terruño, que ha dejado de ser "querido y entrañable", para ser vivido y resignificado en los usos que los grupos sociales dan a "su ciudad". Lo simbólico cedió paso a lo práctico, pero se ha vuelto a resignificar para volver a tener un peso simbólico identificable.

Junto a esto, un imaginario para nuevos actores, cuya poca referencia política, la ausencia de figuras y héroes, da al traste con un desnudamiento de proyectos de vida consistentes y concientes. Hoy lo que importa es vivir el instante, es hacer frente a las tareas laborales, es no desgarrarse ante la ausencia de intereses comunes producto de una falta de preocupación ante lo que quiera decir "participación ciudadana”. Eso sí, la búsqueda de aquellos espacios de esparcimiento y distracción, la necesidad de refugiarse en las Plazas comerciales ante la ola de calor que acorrala los días y las noches porteñas. El deseo de acudir al café o al antro de moda antes que lo cierren ${ }^{2}$, no sólo conforman prácticas, también hábitos y patrones de consumo cultural que lo mismo tipifican opciones que representan intentos por suscribir un tipo de vida que se construye en las interacciones localizadas de los habitantes de estas ciudades.

Por otro lado, las plataformas y agentes de mediación tejen discursos que suelen dar y fortalecer sentido, generando pensum ideológico que condiciona el vivir en estas ciudades costeras. Las ofertas radiofónicas, la cartelera cinematográfica, el acceso a la Internet, los usos de la televisión pagada, el mercado videográfico por encima de otros medios como pudieran ser las empresas editoriales, son agentes que potencian los imaginarios: adultos, jóvenes, niños, hombres y mujeres son interpelados por estas narrativas de "legitimación" urbana, aun cuando sean ponderadas por las trayectorias, las redes sociales o el sentido pertenencia de los propios actores urbanos.

En este orden de ideas, la movilidad intrínseca en cada acción, reproduce alientos prácticos pero igual cognitivos. Es decir, saberes posibles que como dispositivos interfácicos suelen acompañar las conciencias prácticas a la hora de vivir la ciudad. Con otras palabras diríamos, que la praxis que envuelve

${ }^{2}$ Por ejemplo, en Veracruz sólo existen dos antros con más de tres ańos de existencia. Capezzio y La Casona, el primero con 25 años a cuestas y el otro próximo a los 10, son las excepciones. En sus noches es posible identificar formas duras de lealtad para el caso del primero y maneras exquisitas de fidelidad en el segundo. Uno para los sectores populares y el otro para la gente bien de la región.

$374 \bullet$ Genaro Aguirre Aguilar 
diariamente los habitantes de esta conurbación, es el lugar para la construcción de un conocimiento donde las representaciones, los textos mediáticos, los conocimientos científicos se codean y generan un tipo de saber emergente.

Lo que tendríamos que reconocer es que la ciudad es un escenario efervescente, es el lugar para dialogar con otras biografías que producen realidades venidas de rincones, historias y experiencias diversas, que conforman una trama en cuyos bucles y nodos se pudieran reconocer puertos o interfases para el entendimiento y la generación de diálogo por y para los aprendizajes.

\section{Conclusiones}

Todo lo expuesto hasta aquí, consideramos pudiera colocar la experiencia urbana en los albores de un sentido ciudadano distinto. De allí que consideremos necesario ir en pos de la apropiación (dialogada y dialógica) de cada uno de esos rincones citadinos que pueden ser los territorios de nuevos aprendizajes; para lo cual la imaginación y la razón pueden ser parte de un instrumental estratégico para alcanzarlo.

En el entendido de estar frente a la necesidad de un nuevo ordenamiento de vida, creemos que las andanzas cotidianas deben ser cobijadas por un tipo de metodología emergente; es decir, planeada pero sin dejar de ser lúdica, sistemática pero no por ello menos inventiva. Es decir, el atrevimiento y la búsqueda de asombro en aras de los hallazgos. La tarea puede ser tan ardua como la negación lo determine, pero tan generosa como la razón y la creatividad lo quieran. Como siempre, los problemas son los inicios.

Por que sabemos que los retos son enormes, lo que queda a quienes dedicamos parte de la vida a la profesión docente, es atreverse a descentrar el lugar por antonomasia en la producción de conocimientos legitimados; cuanto más, si tras de ese profesor hay una historia que recorrió los caminos de la comunicación como campo disciplinario; pues mejor que nadie sabe lo que representan las plataformas mediáticas en el modelaje de nuevas relaciones sociales, pero también lo que representa la comunicación como de lugar de la experiencia humana.

Denso entramado que halla en la ciudad contemporánea, los espacios y lugares suficientes para la creación de aquellas oportunidades que den pie interacciones más reflexivas entre los sujetos habitantes. Lo que facilitaría el trazado de un nuevo mapa de pertenencia, capaz de generar un paisaje no sólo articulado sino igual matizado por procesos experienciales, en los que la inter- 
vención humana sea capaz de ser gestora de conocimientos en cuyo corazón epistemológico la diversidad sea asumida como dispositivo matriz.

En términos de estructura, desarrollo curricular y gestión académica, la tarea es titánica. Eso lo sabemos, por ello la asunción de nuevos modelos educativos ha dado lugar a la redefinición de otros rumbos en muchas de nuestras instituciones educativas; las mismas que han ido poco a poco generando las mejores condiciones que posibiliten experiencias educativas diferentes a las tradicionales. Las tesis constructivistas han venido a ser un referente, en las que el concepto de transversalidad procura una mirada holística, integral sobre el desarrollo de conocimientos, de competencias y habilidades de los sujetos de la educación. Aquí las asimetrías culturales, la pluralidad de mundos y de realidades posibles, suponen que todo encuentro en terrenos educativos, oriente a la necesidad del establecimiento de estrategias de enseñanza que contribuyan al descentramiento de los aprendizajes, promoviendo autonomías en la constitución de nuevos sujetos de la educación. Implícitamente de lo que hablamos es de rupturas epistemológicas, del desmarcaje de zonas que históricamente nos han dado certidumbre.

Ante lo complejo de los aprendizajes que todo esto demanda, la labor de convencimiento tiene que pasar por distintos estadios, pero hay que empezar por aquellos entornos que nos resultan más cercanos; allí donde coincidimos estudiantes y docentes, reflexionando sobre el propio quehacer y haciendo frente a los temores que suponen la cancelación de ciertas verdades.

Desde una mirada obligada ante lo aquí dicho, valdría preguntarse: ¿cómo aprender de los estadios y andanzas por las ciudades contemporáneas?, ¿a quién corresponde dimensionar un contexto urbano que no sólo puede ser historia sino también presente?, ¿qué podemos hacer en los terrenos educativos para que un puerto como el veracruzano y su zona conurbada pase a ser un escenario público para sistematizar los aprendizajes?, ciudades como ésta, ¿pueden ser lugares estratégicos para comenzar a reinventar nuestras realidades?

En nosotros existe el convencimiento que en un proyecto de esta naturaleza, obligaría a dinámicas más horizontales, más generosas, siempre que nos reconozcamos como parte de una sociedad heterogénea, plural, en la que juntos podemos asumir a la ciudad no sólo como un lugar del estar, sino también del vivir para poder ser... ciudadanos. Vayamos imaginando que desde nuestros ámbitos de intervención educativa, podemos sumar esfuerzos. Comencemos por considerarlo como posible. Todo ello, antes que, como en la película $\mathrm{La}$ historia $\sin$ fin, la nada se apodere de nuestros territorios vitales... los lugares 
del aprendizaje, que como buscamos plantear, pueden ser cualquiera, siempre que las ganas, la imaginación o la inventiva lo permitan. Por todo esto, "Hay que reinventar el modo de convivir" (Martín Barbero, 2005, p. 13).

\section{Bibliografía}

Appadurai, A. (2001). La modernidad desbordada. Dimensiones culturales de la globalización. Argentina: FCE

Augé, M. (1995). Hacia una antropología de los mundos contemporáneos, Barcelona, España: Gedisa.

Barman, B. (2001). El enigma multicultural: Un replanteamiento de las identidades nacionales, étnicas y religiosas. Madrid, España: Paidós.

Borja, J. y Manuel C. (2002). Local y global: La gestión de las ciudades en la era de la información. México: Taurus.

De Fontcuberta, M. (2003). Medios de comunicación y gestión del conocimiento, Revista Iberoamericana de educación, No. 32. Recuperado el 3 de mayo de 2006 de www.rieoei.org/rie32a95.pdf.

Giddens, A. (2004). Un mundo desbocado: Los efectos de la globalización en nuestras vida., México: Taurus.

González, J. A. (2003).Cultura(s) y Ciber_cultur@.. (s). Incursiones no lineales entre Complejidad y Comunicación. México: Universidad Iberoamericana.

Grimson, A. (2001). Interculturalidad y comunicació. Bogotá, Colombia: Norma. Ianni, O. (2000). Enigmas de la modernidad-mundo. México: Siglo XXI. Isaac, J. Irving Goffman y la microsociología. Barcelona, España: Gedissa. Jiménez, G. (1996). Territorio y cultura. México: Universidad de Colima. Lipovetsky, G. (2004), La era del vacío. Barcelona, España: Anagrama Martín-Barbero, J. (2001). De los medios a las mediaciones. Comunicación, cultura $y$ hegemonía. México: Gustavo Gili.

Varios. (2005). La comunicación en la cultura, Cuadernos de Comunicación. Tecnologías/Identidades/Culturas, Facultad de Ciencia Política y RRII, Escuela de Comunicación Social. Postitulo en Periodismo y Comunicación, Universidad Nacional de Rosario. Rosario, Argentina. Pp. 10-14.

Morin, E. (2002). La mente bien ordenada. Barcelona: España: Seix Barral. Varios (2003). Educar en la era planetaria. Barcelona: España: Gedisa.

Sierra, L. I. (2003). Globalización, multiculturalismo y comunicación. Paradojas y debates, Diálogos de la comunicación. Recuperado el 3 de junio de 2006 de www.felafacs.org/dialogos/pdf66/dialogos66.asp.

Tudesco, J. C. (2003). Educar en la sociedad del conocimiento. Buenos Aires, Argentina: FCE. 